\title{
Manubrium sterni stress fracture: an unusual complication of non-contact sport
}

\author{
Kell Robertsen, Ole Kristensen, Lene Vejen
}

\begin{abstract}
Tremendous force is usually required to cause sternal fractures. Normally this is caused either by a direct blow to the chest or by an indirect injury from hyperflexion of the torso. A case is presented of a fracture of the manubrium sterni in a young man as a complication of body building exercises - a non-contact sport. It appears that this has not been reported before.
\end{abstract}

(Br F Sports Med 1996;30:176-177)

Key terms: manubrium sterni; stress fracture; noncontact sports

Fractures of the sternum have occurred with increasing frequency paralleling the incidence of motor vehicle accidents. ${ }^{12}$ Musculoskeletal complications such as fracture and dislocation of the manubriosternal joint in contact sports, for example wrestling, are not uncommon. ${ }^{1}$ Our review of published reports failed to show any previous description of fracture of the manubrium sterni from non-contact sports.

\section{Case report}

A previously healthy 26 year old man, $85 \mathrm{~kg}$ weight and $187 \mathrm{~cm}$ height, was admitted to our department for chest $x$ ray because of anterior chest pain. A week earlier, during a training session, where he performed strenuous abdominal exercises involving 'sit ups', he felt a sudden sharp pain in he upper chest. People around him heard a loud sharp sound. The patient complained of anterior chest pain on movements, and coughing elicited the sternal chest pain. He contacted the local hospital one week later because the pain persisted. There was no history of trauma. There was tenderness to palpation at the manubrium. Sternal $x$ rays revealed a transverse fracture of the manubrium sterni and no other pathology (fig 1). Chest $x$ rays and rib films were reported normal. A computerised tomographic scan (CT) of the thorax revealed no evidence of neoplasm involving the manubrium sterni. The patient was treated with analgesics, and there was no sternal discomfort after eight weeks.

\section{Discussion}

The manubrium sterni is a very rigid and strong bone, because of the attachment to it of the ribs and the clavicles. The clavicle forms a very strong and stable joint at the top of the manubrium. The first rib is attached directly to the body of the manubrium, whereas the second rib has strong ligamentous connections to the manubriosternal joint, ensuring its strength and stability. Fracture of the manubrium is rare. Fracture of the sternum accounts for less than $0.5 \%$ of all traumatic fractures. ${ }^{4}$ Seventy per cent of them are located at the body of the sternum and $17 \cdot 6 \%$ at the manubriosternal joint. ${ }^{5}$ Fractures of the sternum most often occur following direct trauma to the chest, for example "steering wheel" injuries or falls from heights, ${ }^{1}$ but they are also seen following hyperflexion trauma of the torso. The fractures are often accompanied by rib or spine fractures. ${ }^{2}$

In our case the patient was performing strenuous abdominal exercises in the form of "sit ups", raising the upper part of the body

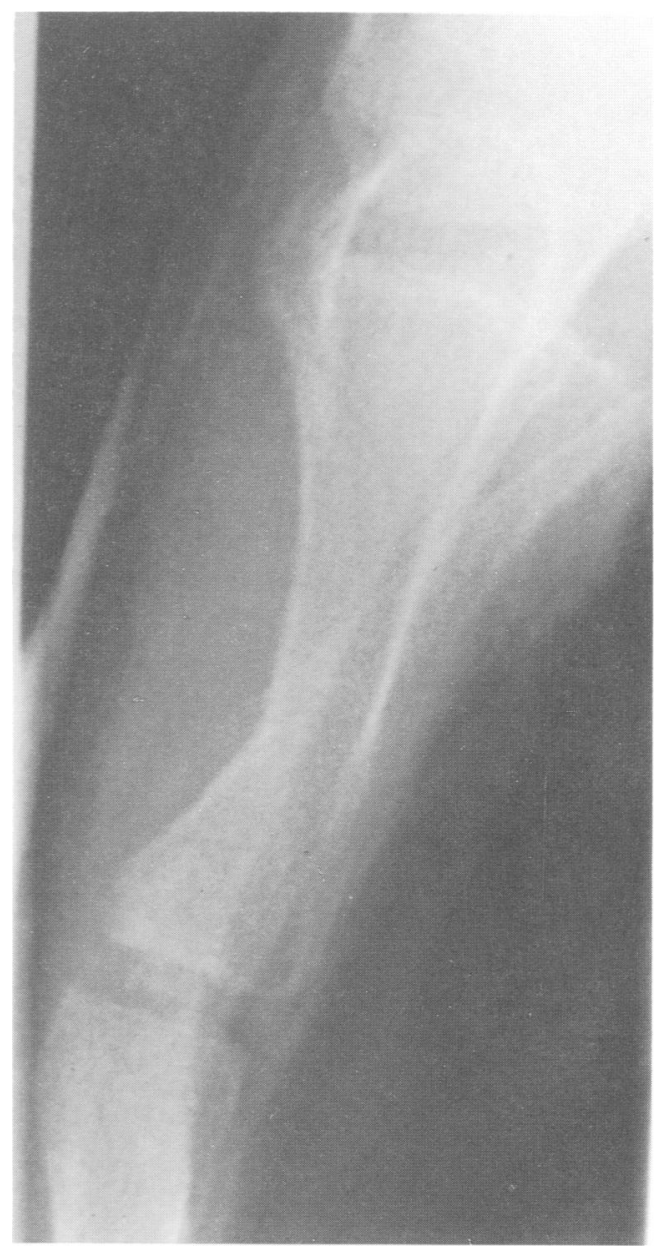

Fig 1 Lateral radiograph of the sternum shows fracture of the manubrium. 


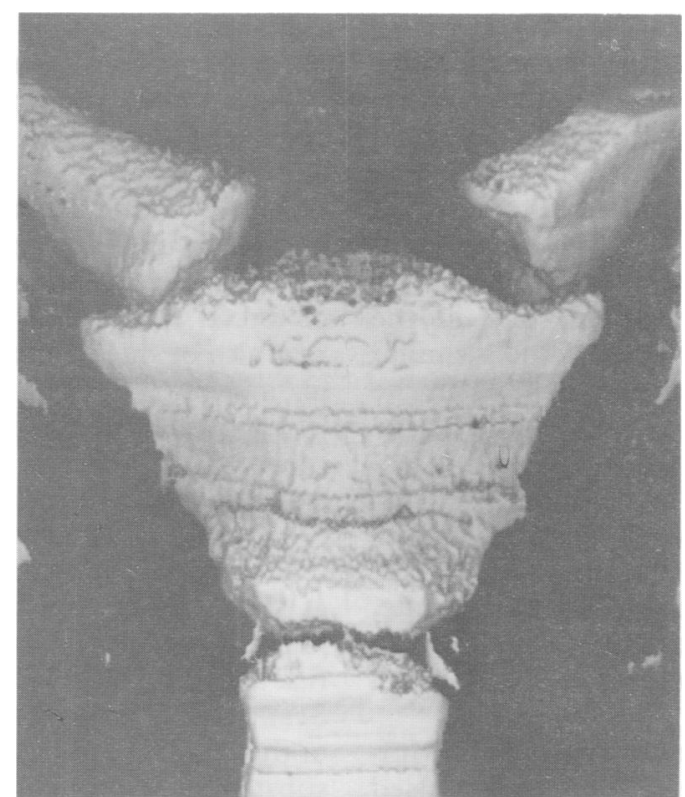

Fig 2 Three dimensional reconstruction reveals a transverse fracture just below the attachment of the first ribs to the manubrium.

from the lying position, when the fracture happend. He had been performing body building exercises every second day for six months. He had trained the pectoralis muscle group each time, using four different sessions inclusive of bench press. He started body building, because he was in very poor condition. The causal mechanism in this case must be found in the muscle attahments and the direction of their forces on the manubrium and sternum. The attachment of the manubrium to the spine through the first and second ribs and the attachment to the shoulders through the clavicles are also part of the mechanism. The sternal head of the sternocleidomastoid and part of the pectoralis major are attached anteriorly to the manubrium and sternum. The sternohyoid and sternothyroid muscles are attached posteriorly to the manubrium, whereas the tranverse thoracis is attached to the posterior surface of the sternum. The very strong rectus abdominis is attached to the distal part of sternum. During sit up exercises hyperflexion of the spine presses the upper part of the manubrium anteriorly, and the contraction of the abdominal and thoracic muscles at the same time add to the fracture angulation.

Computerised tomography scannning with three dimensional reconstruction revealed a transverse fracture just below the attachment of the first ribs to the manubrium (fig 2).

Presumably, the repetitive strenuous training sessions in this formerly untrained patient led to a stress fracture in the manubrium, because the strength of the muscles build up faster than the strength of the bones. Fracturedislocation of the manubriosternal joint has been described as a complication of seizures, ${ }^{3}$ and the mechanism in our case may be somewhat similar.

1 Harley DP, Mena I. Cardiac and vascular sequelae of sternal fractures. 7 Trauma 1986:26:553-5.

2 Jones HK, McBride GG, Mumby RC. Sternal fractures associated with spinal injury. F Trauma 1989;29:360-4.

3 Dastgeer GM, Mikolich DJ. Fracture-dislocation of manubriosternal joint: an unusual complication of seizures. briosternal joint: an un

4 Kurzweg FT, Danna SJ, Lolley RT. Open reduction and fixation of a comminuted fracture of the sternum. fixation of a comminuted fracture

5 Henley MB, Peter RE, Stephen K. External fixation of the sternum for thoracic trauma. $\mathcal{f}$ Orthop Trauma 1991; 5:493.

\section{Orthopaedic}

Directorate,

Queen Elizabeth II

Hospital,

Welwyn Garden City,

Hertfordshire AL7 4HQ,

United Kingdom

N I Munshi, consultant

C E Mbubaegbu,

consultant

Correspondence to:

Chima E Mbubaegbu

FRCSEd.

Accepted for publication

13 July 1995

\title{
Simultaneous rupture of the quadriceps tendon with contralateral rupture of the patellar tendon in an otherwise healthy athlete
}

\author{
N I Munshi, Chima E Mbubaegbu
}

\begin{abstract}
A case of a healthy athlete with simultaneous rupture of quadriceps tendon and rupture of the contralateral patella tendon is reported. Both tendons rupturing in the same patient is rare and this is the first reported case in a previously healthy person. Different mechanisms are implicated in the different ruptures. The rarity is because the simultaneous presence of contributory factors for either injury in the same person is uncommon.

(Br F Sports Med 1996;30:177-178)
\end{abstract}

Key terms: quadriceps tendon; patella tendon; simultaneous rupture; weight lifter.
Bilateral simultaneous rupture of either the infrapatellar tendon or the quadriceps tendon is rare. There are demographic differences in the occurrence of quadriceps and patellar tendon ruptures. ${ }^{1}$ Quadriceps tendon rupture, commoner over the age of 40 , is usually the result of age related changes in the tendon, often associated with degenerative changes in the knee. Patella tendon rupture, on the other hand, occurs in young athletes and is usually attributed to repeated microtrauma. Local or systemic steroids may increase the risk of rupture. $^{2}$

The simultaneous rupture of the quadriceps tendon and contralateral patella tendon in a healthy athlete has as yet not been reported. 